\title{
Analisis Minyak Jelantah Sebagai Bahan Bakar Biodiesel dengan Proses Transesterifikasi
}

\author{
Hadrah*, Monik Kasman, Fitria Mayang Sari \\ Program Studi Teknik Lingkungan, Fakultas Teknik, Universitas Batanghari \\ *e-mail : hadrah.hasan@gmail.com
}

\begin{abstract}
ABSTRAK
Minyak jelantah merupakan minyak bekas yang telah dipergunakan untuk keperluan rumah tangga dan telah mengalami perubahan, baik secara fisik maupun kimia. Salah satu upaya yang dapat dilakukan untuk mengurangi dampak buruk minyak jelantah adalah mengubah minyak jelantah menjadi bahan biodiesel. Pada penelitian ini pembuatan biodiesel dari minyak jelantah dilakukan dengan menggunakan reaksi transesterifikasi seperti pembuatan biodiesel pada umumnya melalui pretreatment guna menurunkan angka asam pada minyak jelantah. Angka asam yang terlalu tinggi akan mempersulit pemisahan gliserol dari biodiesel sehingga produksi biodiesel akan sedikit. Parameter uji kualitas biodiesel yang dihasilkan melalui proses transesterifikasi mengacu pada baku mutu biodiesel Indonesia SNI 7182:2015. Produksi biodiesel dari minyak jelantah pada eksperimen ini menggunakan variasi rasio larutan metanol dan $\mathrm{NaOH}$ terhadap minyak jelantah yaitu $1: 2 ; 1: 4$ dan $1: 8$. Hasil uji menunjukkan bahwa kualitas biodiesel telah memenuhi SNI 7182:2015 pada parameter viskositas, densitas dan uji nyala. Sedangkan Asam lemak bebas masih berada diatas baku mutu SNI 7182:2015.
\end{abstract}

Kata kunci : Minyak jelantah; Transesterifikasi; Biodiesel

\begin{abstract}
Waste cooking oil is used oil that has been used for domestic purposes and has undergone changes, both physically and chemically. One effort that can be done to reduce the adverse effects of used cooking oil is changed the material used cooking oil into biodiesel. In this study of biodiesel production from waste cooking oil is done by using biodiesel transesterification reaction as generally through a pretreatment in order to reduce the number of Free Fatty Acid in cooking oil. The high number of Free Fatty Acid will complicate the separation of glycerol from biodiesel so that production of biodiesel will be slight. Test parameters of biodiesel quality produced by transesterification process refers to the Indonesian biodiesel quality standard ISO 7182: 2015. The production of biodiesel from used cooking oil in this experiment using variations methanol and sodium hydroxide solution ratio to the used cooking oil is 1: 2; $1: 4$ and 1: 8. Test results showed that the quality of biodiesel is in compliance with ISO 7182: 2015 on the parameters of viscosity, density and flame test. While the Free Fatty Acids remained above the quality standard ISO 7182: 2015.
\end{abstract}

Keywords : Waste cooking oil, Transesterification, Biodiesel

\section{Pendahuluan}

Minyak jelantah merupakan limbah yang mengandung senyawa-senyawa yang bersifat karsinogenik yang terjadi selama proses penggorengan (Julianus, 2006). Pemakaian minyak jelantah yang terus-menerus dapat menyebabkan kerusakan pada tubuh manusia seperti penyakit kanker. Sebuah penelitian menyimpulkan bahwa orang-orang yang memasak dan mengkonsumsi makanan yang digoreng dengan minyak jelantah lebih berisiko mengidap tekanan darah tinggi dibandingkan dengan mereka yang sering mengganti minyak gorengnya untuk memasak.

Jumlah produksi minyak jelantah di Indonesia yang telah mencapai 4 juta ton/tahun (Rahkadima, 2011) memerlukan penanganan yang baik agar tidak terjadi pencemaran lingkungan. Pembuangan minyak jelantah secara langsung (tanpa pengolahan) selain dapat mengganggu badan air juga dapat merusak struktur tanah karena menghambat pergerakan air pada pori-pori tanah. Teknologi terbaik yang dapat diterapkan adalah mengolah kembali minyak jelantah yang telah menjadi limbah sehingga memberi manfaat bagi masyarakat.

Salah satu upaya yang dapat dilakukan untuk mengurangi dampak buruk minyak jelantah adalah mengubah minyak jelantah menjadi bahan biodiesel. Biodiesel merupakan salah satu jenis bahan bakar yang diproduksi dengan menggunakan minyak nabati atau lemak hewan melalui proses transesterifikasi atau proses esterifikasi dengan bantuan alkohol dan katalis (Minyak goreng bekas) (Setiawati, 2012).

Biodiesel mempunyai keunggulan dibandingkan dengan bahan bakar diesel dari minyak bumi. Keunggulan dari biodiesel yaitu bahan bakar biodiesel dapat diperbaharui, ramah lingkungan, aman dalam penyimpanan dan transportasi karena tidak mengandung racun serta dapat memperkuat perekonomian negara dan menciptakan lapangan kerja (Sudradjat, 2008). 
Pembuatan biodiesel dari minyak jelantah ini menggunakan reaksi transesterifikasi seperti pembuatan biodiesel pada umumnya, dengan pretreatment guna menurunkan angka asam pada minyak jelantah. Angka asam yang terlalu tinggi akan mempersulit pemisahan gliserol dari biodiesel sehingga produksi biodiesel akan sedikit.

Ketentuan paling penting dalam pembuatan biodiesel adalah kadar ester (minimal 96,5\%), bilangan asam (maksimum 0,5 mg KOH/gr).Kadar ester dipengaruhi oleh kualitas teknologi dan proses yang digunakan, serta komposisi bahan baku yang digunakan. Selain itu, parameter penting lainnya berupa kandungan sulfur, fosfor, logam alkali, total kontaminasi, dan hasil gliserol yang tidak bereaksi.

Teknologi proses produksi biodiesel yang berkembang saat ini dapat dikelompokkan menjadi proses satu tahap (transesterifikasi) dan proses dua tahap (esterifikasi-transesterifikasi). Sedangkan minyak yang memiliki nilai Free Fatty Acid (FFA) di atas 1\%, seperti minyak goreng bekas, sebaiknya menggunakan proses dua tahap (esterifikasi-transesterifikasi). Minyak yang mengandung asam lemak bebas lebih dari $1 \%$ akan membentuk formasi emulsi sabun yang menyulitkan pada saat pemisahan biodiesel.

Minyak goreng bekas merupakan minyak yang kadar asam lemak bebasnya meningkat akibat dari proses pemanasan yang terus menerus, sehingga proses pembuatan biodiesel dari minyak goreng bekas biasanya dilakukan melalui dua tahap proses yaitu esterifikasi dan transesterifikasi. Menurut Julianus (2006), tahap esterifikasi diperlukan untuk mengesterifikasi asam lemak bebas Free Fatty Acid (FFA) dalam minyak bekas agar jumlahnya tidak terlalu banyak. Asam lemak bebas yang terlalu banyak akan membentuk banyak sabun sehingga akan mengurangi produksi biodiesel.

\section{Transesterifikasi}

Transesterifikasi adalah proses transformasi kimia molekul trigliserida yang besar, bercabang dari minyak nabati dan lemak menjadi molekul yang lebih kecil, molekul rantai lurus, dan hampir sama dengan molekul dalam bahan bakar diesel. Minyak nabati atau lemak hewani bereaksi dengan alkohol (biasanya metanol) dengan bantuan katalis (biasanya basa) yang menghasilkan alkil ester (atau untuk metanol, metil ester) (Knothe et al., 2005 dalam herlina 2014)

Reaksi transesterifikasi trigliserida menjadi metil ester adalah :

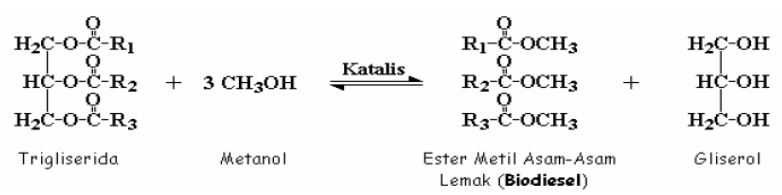

Transesterifikasi juga menggunakan katalis dalam reaksinya. Tanpa adanya katalis, konversi yang dihasilkan maksimum namun reaksi berjalan dengan lambat. (Mittlebatch, 2004). Katalis yang bisa digunakan pada reaksi transesterifikasi adalah katalis basa, karena katalis ini dapat mempercepat reaksi.

Reaksi transesterifikasi sebenarnya berlangsung dalam 3 tahap yaitu sebagai berikut :

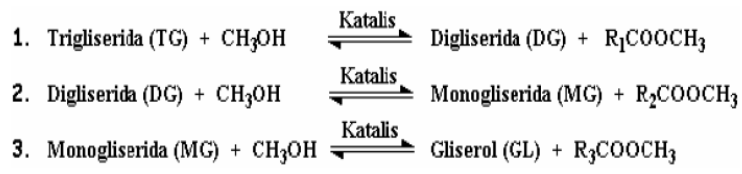

Tidak seperti esterifikasi yang mengkonversi asam lemak bebas menjadi ester, pada transesterifikasi yang terjadi adalah mengubah trigliserida menjadi ester. Perbedaan antara transesterifikasi dan esterifikasi menjadi sangat penting ketika memilih bahan baku dan katalis. Transesterifikasi dikatalisis oleh asam atau basa, sedangkan esterifikasi, bagaimanapun hanya dikatalisis oleh asam (Nourredine, 2010).

\section{Faktor-faktor yang Mempengaruhi Reaksi Transesterifikasi}

Menurut Arpiwi (2015), faktor-faktor yang mempengaruhi reaksi transesterifikasi adalah sebagai berikut:

\section{Lama Reaksi}

Semakin lama waktu reaksi semakin banyak produk yang dihasilkan karena keadaan ini akan memberikan kesempatan terhadap molekul-molekul reaktan untuk bertumbukan satu sama lain. Namun setelah kesetimbangan tercapai tambahan waktu reaksi tidak mempengaruhi reaksi.

\section{Rasio perbandingan alkohol dengan minyak}

Rasio molar antara alkohol dengan minyak nabati sangat mempengaruhi dengan metil ester yang dihasilkan. Semakin banyak jumlah alkohol yang dugunakan maka konversi ester yang dihasilkan akan bertambah banyak. Perbandingan molar antara alkohol dan minyak nabati yang biasa digunakan dalam proses industri untuk mendapatkan produksi metil ester yang lebih besar dari $98 \%$ berat adalah $6: 1$.

\section{Jenis katalis}

Katalis adalah suatu zat yang berfungsi mempercepat laju reaksi dengan menurunkan energi aktivasi, namun tidak menggeser letak keseimbangan. Penambahan katalis bertujuan untuk mempercepat reaksi dan menurunkan kondisi operasi. Tanpa katalis reaksi transesterifikasi baru dapat berjalan pada suhu $250^{\circ} \mathrm{C}$. Ketika reaksi selesai, kita akan mendapatkan massa katalis yang sama seperti pada awal kita tambahkan. Katalis yang dapat digunakan dapat berupa katalis homogen atau heterogen.

\section{Suhu}

Kecepatan reaksi transesterifikasi akan meningkat pada suhu yang mendekati titik didih alhohol yang digunakan. Suhu selama reaksi transesterifikasi dapat dilakukan pada rentang suhu $30^{\circ} \mathrm{C}-65^{\circ} \mathrm{C}$ dan dijaga selama proses, tergantung dari jenis minyak yang digunakan. Dalam proses transesterifikasi perubahan 
suhu reaksi menyebabkan gerakan molekul semakin cepat sehingga bisa mengatasi energi aktivasi. Suhu mempengahuhi viskositas dan densitas, karena viskositas dan densitas merupakan dua parameter fisis penting yang mempengaruhi pemanfaatan biodiesel sebagai bahan bakar. Semakin tinggi suhu menyebabkan gerakan molekul semakin cepat atau energi kinetik yang dimiliki molekul-molekul pereaksi semakin besar sehingga tumbukan antara molekul pereaksi juga meningkat .

\section{Pengadukan}

Peningkatan kecepatan pengadukan meningkatkan kecepatan reaksi karena dengan pengadukan akan mempercepat pergerakan molekul dan memperbesar peluang terjadinya tumbukan antar molekul.

\section{Lama Waktu Pengendapan (Settling)}

Lama waktu pengendapan berpengaruh pada proses tranesterifikasi 2 tahap yaitu melakukan dua kali proses transesterifikasi. Pengendapan bertujuan untuk memisahkan gliserol dan biodiesel. Waktu pengendapan metil ester mempengaruhi bilangan asam. Ketika pengendapan yang lebih lama, diduga tingkat oksidasi pada proses dua tahap lebih tinggi dari pada proses satu tahap. Hal ini mengakibatkan bilangan asam menjadi lebih tinggi.

\section{Kandungan Air}

Kandungan air yang berlebihan dapat menyebabkan sebagian reaksi dapat berubah menjadi reaksi sabun atau saponifikasi yang akan menghasilkan sabun, sehingga meningkatkan viskositas, terbentuknya gel dan dapat menyulitkan pemisahan antara gliserol dan Biodiesel.

\section{Methanol}

Jenis alkohol yang selalu dipakai pada proses transesterifikasi adalah metanol dan etanol. Metanol merupakan jenis alkohol yang paling disukai dalam pembuatan biodiesel karena methanol $\left(\mathrm{CH}_{3} \mathrm{OH}\right)$ mempunyai keuntungan lebih mudah bereaksi atau lebih stabil dibandingkan dengan etanol $\left(\mathrm{C}_{2} \mathrm{H}_{5} \mathrm{OH}\right)$ karena metanol memiliki satu ikatan carbon sedangkan etanol memiliki dua ikatan karbon, sehingga lebih mudah memperoleh pemisahan gliserol dibanding dengan etanol.

\section{Kosolven}

Pembuatan biodiesel merupakan reaksi yang lambat karena berlangsung dalam dua fase, permasalahan tersebut dapat di atasi dengan penambahan kosolven kedalam campuran minyak nabati, metanol dan katalis, sehingga penambahan kosolven bertujuan untuk membentuk sistem larutan menjadi berlangsung dalam satu fase. Reaksi transesterifikasi tanpa kosolven ternyata berlangsung lambat dan menghasilkan metil ester yang kurang signifikan dibanding penambahan kosolven (Baidawi, A., 2007), Hal ini terjadi karena adanya perbedaan kelarutan antara minyak nabati dengan metanol, dalam metanol campuran reaktan membentuk dua lapisan (membentuk dua fase) dan diperlukan waktu beberapa saat agar minyak nabati dapat larut di dalam metanol.

\section{Metode Penelitian}

Sampel yang digunakan adalah minyak goreng bekas 2 - 3 kali penggorengan dari aktivitas rumah makan dan katering di Kota Jambi. Pengujian kualitas biodiesel dilakukan di Laboratorium Lingkungan Fakultas Teknik Universitas Batanghari Jambi. Penelitian dilakukan pada bulan (Juli - November 2017).

Alat yang dipakai pada penelitian ini yaitu gelas ukur, labu ukur, erlenmeyer, gelas beaker, pipet tetes, pipet ukur, batang pengaduk, magnetic stirrer, gelas kaca, timbangan, filler, spatula logam, corong gelas, hot plate, buret, piknometer, stopwatch, bola logam, pemanas bunsen, mikrometer skrup. Bahan-bahan yang digunakan pada percobaan ini yaitu minyak jelantah, asam asetat, $\mathrm{NaOH}$, Air, Methanol 99\%, Indikator PP, dan Aquades.

\section{Pembuatan Reagen}

- $\quad$ Larutan indikator Phenolphthalein (PP) 0,5\% Timbang 0,5 gram Phenolphthalein dan larutkan dalam $100 \mathrm{ml}$ alkohol dalam labu ukur $100 \mathrm{ml}$.

- Larutan $\mathrm{NaOH} 0,1 \mathrm{~N}$ Timbang 1 gram $\mathrm{NaOH}$ dan masukkan dalam labu ukur $250 \mathrm{ml}$, lalu larutkan dengan air suling.

\section{Pembuatan Biodiesel}

Cara pembuatan biodiesel dari minyak jelantah dengan proses transesterifikasi.

1. Minyak jelantah dipanaskan sampai suhu $100^{\circ} \mathrm{C}$ untuk menghilangkan kandungan airnya. Gunakan alat pengaduk untuk pengaduk untuk memudahkan penghilangan uap air. Setelah air yang mendidih dalam minyak mulai hilang, selanjutnya panaskan sampai suhu $130^{\circ} \mathrm{C}$ selama 10 menit dan dinginkan.

2. Titrasi untuk menentukan banyaknya katalis $(\mathrm{NaOH})$ yang diperlukan dengan cara :

a) Siapkan alat titrasi terdiri buret dan gelas piala kecil.

b) Siapkan larutan 1 gram $\mathrm{NaOH}$ ke dalam 1 liter air suling (larutan $0,1 \% \mathrm{NaOH}$ ).

c) Larutkan $1 \mathrm{ml}$ minyak jelantah ke dalam $10 \mathrm{ml}$ isopropil alkohol dipanaskan sambil diaduk sampai campuran jernih.

d) Tambahkan 2 tetes larutan PP.

e) Isi buret dengan larutan $\mathrm{NaOH} 0,1 \%$, teteskan larutan tersebut tetes demi tetes ke dalam larutan minyak jelantah-alkohol-PP, sambil diaduk sampai larutan berwarna merah muda selama 10 detik.

f) Lihat pada buret, volume $(\mathrm{ml})$ larutan $0,1 \%$ $\mathrm{NaOH}$ yang digunakan dan tambahkan 5 maka ketemu jumlah gram $\mathrm{NaOH}$ yang diperlukan perliter minyak. 
3. Pendiaman dan pemisahan metil ester (minyak biodiesel) dengan gliserin. Cara pemisahannya adalah :

a) Proses dibiarkan sampai sempurna sedikitnya 8 jam dan suhu dipertahankan pada $38^{\circ} \mathrm{C}$.

b) Biodiesel akan berada di bagian atas dan gliserin ada dibagian bawah berwarna coklat gelap. Gliserin merupakan cairan kental yang dapat memadat dibawah suhu $38^{\circ} \mathrm{C}$.

c) Alirkan gliserin dengan hati-hati dari bagian bawah reaktor, sehingga biodiesel dapat dipisahkan kemudian ditempatkan di wadah lain.

d) Apabila gliserin memadat maka dapat dipanaskan kembali agar mencair.

e) Gliserin masih bercampurkan dengan sisa reaktan dan alkohol, maka dinetralisasi menggunakan asam mineral dan dipanaskan pada suhu $66^{\circ} \mathrm{C}$ untuk mengambil kembali alkohol, sehingga diperoleh gliserin kemurnian tinggi.

4. Hasil biodiesel sering tercampur dengan sabun. Biodiesel dicuci menggunakan air suling untuk menghilangkan sabun dan sisa-sisa bahan lain. Proses pencuciannya adalah sebagai berikut :

a) Pada pencucian pertama, biodiesel ditambah sedikit larutan asam asetat, kemudian diaduk agar terjadi netralisasi.

b) Tuangkan air suling dalam wadah, kemudian dituangi biodiesel yang akan dicuci, kemudian diaduk.

c) Setelah didiamkan antara 12-24 jam, minyak biodiesel akan terpisah dengan air pencuci. d) Minyak yang telah bersih dialirkan untuk memisahkan dengan air yang mengandung sabun.

e) Proses pencucian ini diulang 2-3 kali, tanpa penambahan asam. Pada pencucian ketiga, biodiesel hasil pencucian dipanaskan untuk menghilangkan air yang masih terikut. $\mathrm{pH}$ biodiesel hasil pencucian mempunyai $\mathrm{pH} 7$ (netral)

5. Pengecekan kualitas biodiesel. Biodiesel yang akan digunakan untuk bahan bakar mesin diesel seperti pada mobil memerlukan kualitas biodiesel yang tinggi.

\section{Hasil dan Pembahasan}

Produksi biodiesel dari minyak jelantah pada eksperimen ini menggunakan variasi komposisi metanol dan $\mathrm{NaOH}$ serta rasio larutan metanol dan $\mathrm{NaOH}$ terhadap minyak jelantah yaitu $1: 2 ; 1: 4$ dan $1: 8$ seperti terlihat pada Tabel 1.

Berdasarkan hasil uji kualitas biodiesel dapat disimpulkan bahwa biodiesel minyak jelantah telah memenuhi standar baku mutu kecuali asam lemak bebas (FFA) seperti terlihat pada Tabel 2.

Tabel 1. Perbandingan Rasio Metanol dan $\mathrm{NaOH}$ pada

\begin{tabular}{lccc}
\multicolumn{4}{c}{ Sampel } \\
\hline Bahan Baku & \multicolumn{1}{c}{$\begin{array}{c}\text { Sampel 1 } \\
(\mathbf{1 : 2})\end{array}$} & $\begin{array}{c}\text { Sampel 2 } \\
(\mathbf{1 : 4})\end{array}$ & $\begin{array}{c}\text { Sampel 3 } \\
(\mathbf{1 : 8})\end{array}$ \\
\hline $\begin{array}{l}\text { Minyak } \\
\text { jelantah }(\mathrm{ml})\end{array}$ & 500 & 500 & 500 \\
NaOH $(\mathrm{gr})$ & 3,5 & 3,5 & 3,5 \\
Metanol $99 \%$ & 100 & 125 & 175 \\
$(\mathrm{ml})$ & & & \\
Sumber : Data Primer & &
\end{tabular}

Tabel 2. Hasil Uji Kualitas Biodiesel

\begin{tabular}{ccccc}
\hline Parameter & \multicolumn{3}{c}{ Hasil Penelitian } & Baku Mutu \\
\cline { 2 - 4 } & Sampel 1 & Sampel 2 & Sampel 3 & $0,85-0,87$ \\
Densitas (gr/ml) & 0,87 & 0,87 & 0,87 & 0,8 \\
Asam lemak bebas (\%) & 1,22 & 1,01 & 1,42 & $2,3-6,0$ \\
Viskositas kinematic $\mathrm{mm}^{2} / \mathrm{s}(\mathrm{cSt})$ & 3,93 & 4,01 & 4,31 & Menyala \\
Uji nyala & Menyala & Menyala & &
\end{tabular}

Jumlah metanol tidak berpengaruh terhadap densitas biodiesel namun besarannya menunjukkan bahwa densitas biodiesel yang dihasilkan telah memenuhi persyaratan pada spesifikasi minyak biodiesel yaitu 0,87 $\mathrm{gr} / \mathrm{ml}$ (Gambar 1). Densitas yang diperoleh telah memenuhi standar baku mutu SNI 7182:2015 yaitu 0,85 - $0,87 \mathrm{gr} / \mathrm{ml}$.

Hasil penelitian ini sejalan dengan penelitian Adhari, dkk (2016), didapatkan densitas biodiesel yang dihasilkan yaitu $866,50 \mathrm{~kg} / \mathrm{m} 3$ sudah sesuai dengan standar SNI. Jika nilai densitas biodiesel sesuai dengan standar mutu (SNI) maka penggunaannya dapat menghasilkan pembakaran yang sempurna, sedangkan biodiesel dengan densitas yang melebihi standar SNI akan menyebabkan reaksi pembakaran yang tidak sempurna sehingga dapat meningkatkan emisi dan keausan mesin.

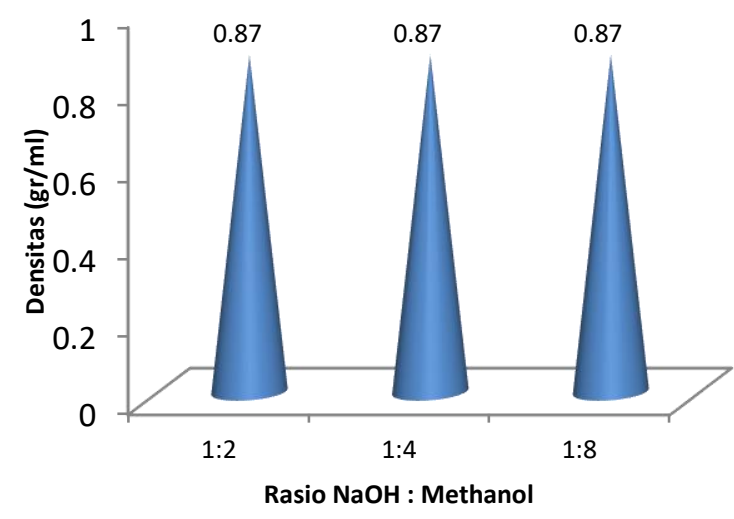

Gambar 1. Grafik Pengaruh Rasio Methanol dan $\mathrm{NaOH}$ terhadap Densitas Biodiesel 


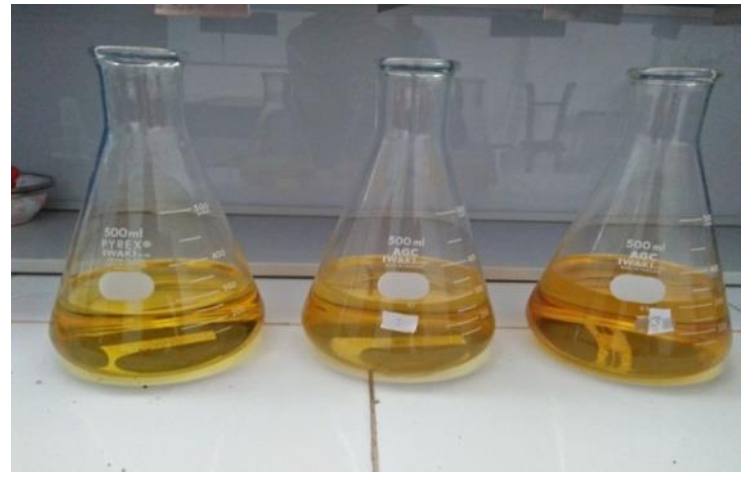

Gambar 2. Biodiesel dari Minyak Jelantah

Pada Gambar 2 terlihat bahwa secara fisik tidak tampak perbedaan biodiesel yang dihasilkan dengan variasi rasio $\mathrm{NaOH}$ dan Methanol namun pengujian nilai asam lemak dan viskositas biodiesel menunjukkan terdapat perbedaan kualitas biodiesel yang dihasilkan.

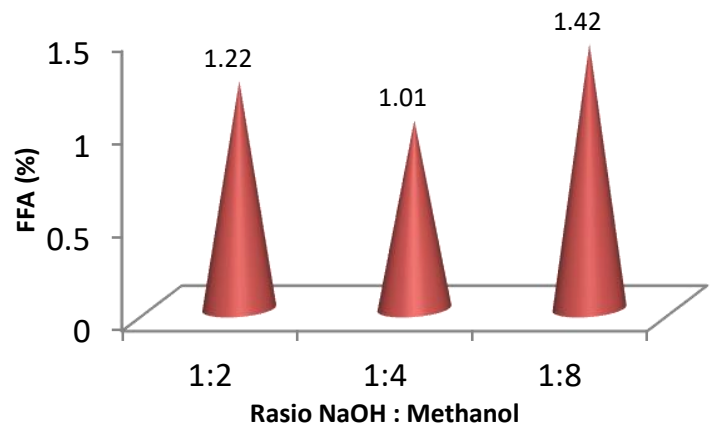

Gambar 3. Grafik Pengaruh Rasio Methanol dan $\mathrm{NaOH}$ terhadap Asam Lemak Bebas Biodiesel

Gambar 3 menunjukkan bahwa asam lemak bebas pada biodiesel masih tinggi yaitu 1,22\%, 1,01\%, 1,42\%. Hal ini perlu pengurangan kadar air dan kadar asam lemak bebas dengan menggunakan esterifikasi metanol dengan katalisator asam sehingga belum memenuhi spesifikasi minyak biodiesel. Dapat disimpulkan bahwa asam lemak bebas (FFA) yang diperoleh tidak memenuhi standar baku mutu yaitu $0,8 \%$

Hasil ini sejalan dengan penelitian Rhofita (2015), dimana kadar asam lemak bebas yang didapatkan adalah sebesar 9,67\%. Kandungan minyak jelantah yang tinggi asam lemak (free fatty acid/FFA) memerlukan dua kali proses dalam pembuatan biodiesel. Proses pertama adalah esterifikasi dengan menggunakan katalis asam dan proses kedua adalah transesetrifikasi dengan menggunakan katalis basa.

Gambar 4 menunjukkan bahwa viskositas biodiesel yang dihasilkan telah memenuhi persyaratan pada spesifikasi minyak biodiesel yaitu sebesar 3,93 Cst, 4,01 Cst, 4,31 Cst. Dapat disimpulkan bahwa viskositas yang diperoleh telah memenuhi standar baku mutu SNI 7182:2015 yaitu 2,3 - 6,0 Cst.

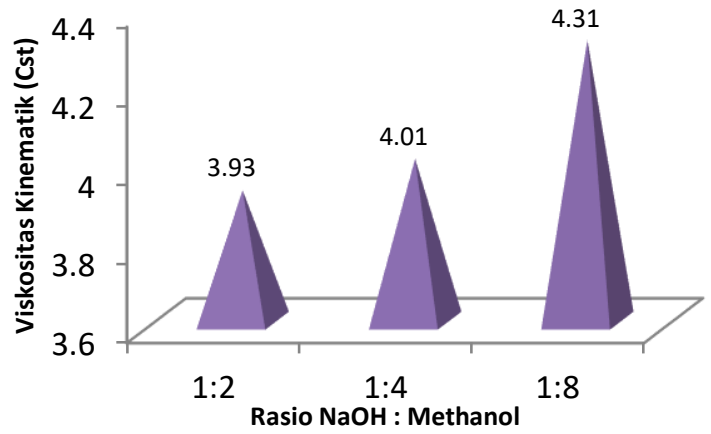

Gambar 4. Grafik Pengaruh Rasio Methanol dan $\mathrm{NaOH}$ terhadap Viskositas Biodiesel

Selain parameter densitas, viskositas dan asam lemak bebas juga dilakukan uji nyala pada biodiesel dengan menggunakan Bunsen sebagai alat pembakaran. Hasil uji menunjukkan terjadi pembakaran yang menandakan biodiesel dapat digunakan sebagai bahan bakar.

\section{Kesimpulan dan Saran}

Rasio komposisi metanol dan $\mathrm{NaOH}$ berpengaruh terhadap kualitas biodiesel dari minyak jelantah yaitu pada parameter viskositas dan asam lemak bebas biodiesel. Hasil pengujian nilai viskositas kinematik pada rasio penggunaan metanol dan $\mathrm{NaOH}$ terhadap minyak jelantah 1:2, 1:4, 1:8 secara berurutan yaitu 3,93 Cst, 4,01 Cst, 4,32 Cst sehingga dapat disimpulkan bahwa nilai viskositas kinematik semakin kecil seiring penambahan jumlah methanol. Hasil uji menunjukkan bahwa kualitas biodiesel telah memenuhi SNI 7182:2015 pada parameter viskositas, densitas dan uji nyala. Sedangkan Asam lemak bebas tidak memenuhi standar SNI.

Berdasarkan percobaan pembuatan biodiesel dari minyak jelantah yang dilakukan, diketahui bahwa untuk mendapatkan sifat fisis biodiesel yang memenuhi kriteria standar mutu biodiesel (SNI 7182:2015) maka diperlukan perlakuan lebih lanjut terhadap ester minyak jelantah, yakni pengurangan kadar air dan kadar asam lemak bebas (FFA) dengan menggunakan reaksi esterifikasi metanol dengan katalisator asam, sehingga diperoleh penurunan kadar asam lemak bebas (FFA).

\section{Daftar Pustaka}

Adhari, H., Yusnimar, Utami, S. P. (2016). Pemanfaatan Minyak Jelantah menjadi Biodiesel dengan Katalis $\mathrm{ZnO}$ Presipitan Zinc Karbonat : Pengaruh Waktu Reaksi dan Jumlah Katalis, Jom FTEKNIK Vol. (3), 1-7

Arpiwi, N. L. (2015). Produksi Biodiesel dari Biji Malapari (Pongamia pinnata (L.) Pierre). Karya Tulis Jurusan Biologi Fakultas MIPA Universitas Udayana.

Budiawan, R., Zulfansyah., Fatra, W., dan Helwani, Z. (2013). Off-grade Palm Oil as a Reneweble Raw Material for Biodiesel Production By Two-Step Processes. ChESA Conference. Januari. Banda Aceh. Chemical Engineering on Science and Application. $7: 40-50$.

Dising, Julianus. (2006). Optimasi Proses Pembuatan Biodiesel dari Minyak Jelantah. Makassar : Jurusan Teknik Kimia UKI Paulus. 
Hikmah. M. N dan Zuliyana. (2010). Pembuatan Metil Ester (Biodiesel) Dari Minyak Dedak Dan Metanol Dengan Proses Esterifikasi Dan Transesterifikasi. Skripsi. Universitas Diponegoro. Semarang.

Knothe G, JV Gerpen and J. Krahl. (2005). The Biodiesel Handbook. United States of America: AOCS Press.

Listiadi A. P., dan I. M. B. Putra. (2013). Intensifikasi Biodiesel dari Minyak Jelantah dengan Metode Interesterifikasi dan Pemurnian Dry Washing. Skripsi. Universitas Sultan Ageng Tirtayasa. Cilegon.

Majid, Atsari. A, dkk. (2012). Pembuatan Biodiesel Dari Minyak Jelantah Dengan Menggunakan Iradiasi Gelombang Mikro. Skripsi Universitas Sebelas Maret. Surakarta.

Nourredine, Abdoulmoumine, (2010). Sulfate and Hydroxide Supported on Zirconium Oxide Catalysts for Biodiesel
Production, Thesis, Virginia Polytechnic Institute and State University, Blacksburg, Virginia.

Rahkadima, Y., dan Purwati, P. A. (2011). Pembuatan Biodiesel dari Minyak Jelantah Melalui Proses Transesterifikasi Dengan Menggunakan CaO Sebagai Katalis.

Rhofita, E I. (2015). Pemanfaatan Minyak Jelantah Sebagai Biodiesel : Kajian Temperatur dan waktu Reaksi Transesterifikasi. Skripsi. Jurnal Ilmu-ilmu Teknik Sistem, Vol. 12 No.3.

Setiawati. E. Edwar. F. (2012). Teknologi Pengolahan Biodiesel Dari Minyak Goreng Dengan Teknik Mikrofitrasi dan transesterifikasi sebagai Alternatif Bahan Bakar Mesin Diesel. Balai Riset dan standarisasi Industri Banjarbaru.

Sudradjat. (2008). Memproduksi Biodiesel Jarak Pagar. Jakarta : Swadaya. 